\title{
The Measurement of the Exchangeable Pools of Cholesterol in the Baboon
}

\author{
JEAN D. WiLson \\ From the Department of Internal Medicine, The University of Texas \\ Southwestern Medical School, Dallas, Texas 75235
}

\begin{abstract}
A B S T R A C T Five male baboons were fed cholesterol$1 \alpha-{ }^{3} \mathrm{H}$ until an isotopic steady state was approached in which the ratio of serum to dietary cholesterol specific activity was constant. The animals were then given single intravenous injections of cholesterol- $4{ }^{14} \mathrm{C}$, and the disappearance curves of the ${ }^{14} \mathrm{C}$ from the circulation were followed for 70-85 days. The total exchangeable cholesterol pools under these conditions were determined by carcass analysis at the end of the experiment and were shown to agree closely with the sums of the two exchangeable cholesterol pools as predicted from analysis of the die-away curve in terms of a two exchangeable pool model, assuming that entry into and exit from the system occur predominantly through the more rapidly exchanging of the two pools. These results have been interpreted as support for the validity of a model consisting of two exchangeable pools and one nonexchangeable or very slowly exchangeable pool as an approximation of over-all cholesterol metabolism in this species. In addition, an anatomical and chemical dissection of these pools was performed. While the three pool model is not applicable to every tissue, it has been possible to show that its general applicability in the intact animal stems from the fact that the major portions of the three cholesterol pools of the body lie within a limited number of tissues.
\end{abstract}

\section{INTRODUCTION}

The turnover curve of plasma cholesterol specific activity after the administration of a single dose of radioactive cholesterol to man has recently been analyzed in detail by Goodman and Noble (2). These authors demonstrated that in every study cholesterol turnover con-

This report has been published in abstract form (1).

Dr. Wilson is a recipient of a Career Development Award of the U. S. Public Health Service.

Received for publication 7 July 1969 and in revised form 1 December 1969. formed to a two exchangeable pool model of the type described by Gurpide, Mann, Sandberg, and Lieberman in which the specific activity is described by the equation $\mathrm{C}_{\mathrm{A}} \mathrm{e}^{-\alpha t}+\mathrm{C}_{\mathrm{B}} \mathrm{e}^{-\beta t}(3,4)$. (The version of the model used in this paper is described in Fig. 1, and the analyses derived from it are formulated in the Appendix.) Evidence in support of the general validity of this model has been advanced by three additional studies. Samuel, Holtzman, Meilman, and Perl (5), and Nestel, Whyte, and Goodman (6) have also observed that the disappearance curve can be subjected to two compartmental analysis (5), and Grundy and Ahrens have demonstrated that turnover rates calculated on the basis of a two compartment system conform closely to values obtained from sterol balance ( 7$)$.

The implications of this formulation for the elucidation both of normal and deranged cholesterol metabolism are considerable, since, if correct, it allows the estimation in the intact subject not only of the rate constants for the removal of cholesterol from and the exchange of cholesterol between the pools and of the production or turnover rate, but of the size of the pools as well. However, the quantification of the exchangeable pool size in this manner has been thought to be subject to a severe limitation: in the original description of the two pool model it was assumed that although the independent exit of cholesterol from pool $\mathrm{B}\left(k_{\mathrm{B}}\right)$ was negligible, the entry of cholesterol into pool B from outside the system $\left(s_{B}\right)$ was likely to be significant (2). Thus, while the size of the rapidly exchangeable pool $A$ could be estimated with theoretical soundness, pool B, the more slowly exchanging compartment, could not be estimated in the absence of a means of quantifying $\boldsymbol{s}_{\mathbf{B}}$. A similar assumption was made by Samuel et al. (5) and by Nestel, Whyte, and Goodman (6) who, as the result of calculating limit cases for various values of $s_{\mathrm{B}}$ and $k_{\mathrm{B}}$ concluded that directional changes but not the absolute size of pool B could be estimated in the terms of this model. 


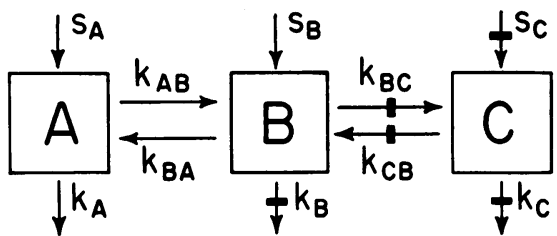

Figure 1 The over-all model of cholesterol metabolism in the intact animal. The general two pool ( $A$ and $B$ ) model of Goodman and Noble (2) has been altered by the addition of a nonexchangeable pool C. For the purposes of this paper pool $\mathrm{C}$ is defined as that pool which does not equilibrate with the serum after 4 months of feeding cholesterol ${ }^{3} \mathrm{H}$; pool $\mathrm{C}$ may include very slowly exchanging compartments as well as truly nonexchanging pools. Rate constants are denoted by the $k$ values; $s$ values are the rates of entry of material into the pools from outside the system. Crossed arrous indicate constants which were assumed to approximate zero by Goodman and Noble $\left(k_{\mathrm{B}}\right)$ or which are generally assumed to approximate zero.

However, at least two lines of evidence from this laboratory suggest that independent entry of cholesterol into pool B is very small indeed. First, when assayed under in vitro conditions approaching zero order kinetics, two tissues, the liver and gastrointestinal tract, account for $97 \%$ of the total cholesterol synthesized in the squirrel monkey (8), and it is clear that these compartments exchange rapidly with the circulation and must therefore comprise a portion of the more rapidly exchangeable of the pools. Second, when hepatic cholesterol synthesis is suppressed and the intestinal contribution is diverted from the circulation, no radioactive cholesterol appears in the blood stream of the monkey for as long as $48 \mathrm{hr}$ after the administration of acetate $-{ }^{14} \mathrm{C}(9)$. While this time period is of course too short for complete equilibration between the two exchangeable pools, cholesterol ${ }^{14} \mathrm{C}$ would be detectable in serum within 2 days if $s_{\mathrm{B}}$ were significant. The suggestion that $s_{\mathbf{B}}$ is negligible does not imply of course that it is zero, only that it is so small in relation to $s_{\Delta}$ that it can be assumed to approximate zero. Indeed, this situation also holds for $k_{\mathrm{B}}$ since the cholesterol desquamated from the skin, urinary tract, cerumen, and nasal secretions is presumed to be negligible only in relation to the discrepant amount excreted via the gastrointestinal tract. At any rate, if $k_{\mathrm{B}}$ as well as $s_{\mathrm{B}}$ approximates zero then the size of $B$ is a function of the rate constants of exchange between the two exchangeable pools (3).

The experiments to be described in this report were designed first to explore the measurement of the overall body pools of cholesterol by determining in the intact animal whether independent movement of cholesterol into and out of pool B is, in fact, negligible. In five baboons in an apparent isotopic steady state the total exchangeable cholesterol pool has been measured by direct carcass analysis and has been shown to agree closely with the sum of [A] and [B] estimated in the same animals by analysis of the die-away curves. It has been concluded that an analysis of the cholesterol turnover curve in terms of the two exchangeable pool model, assuming that the major entry into and exit from pool $\mathrm{B}$ occurs through pool $\mathrm{A}$, does provide a valid means for estimating both exchangeable pools of cholesterol in this species. In addition, an anatomical and chemical dissection of individual tissues has been undertaken in these same animals in order to examine the compartmentalization of cholesterol within discrete organs. These two types of studies provide a means for examining the meaning of the pool analyses in physiological terms.

\section{METHODS}

Treatment of the animals. Five male baboons were obtained from the Southwest Foundation for Research and Education; the taxonomy of the baboon is controversial (10), and no further attempt was made to classify them other than as Papio genus. The animals which were classed as mature adults were maintained in individual squeeze cages and allowed free access to water. Each animal was fed twice daily a weighed quantity of diet which totaled $275 \mathrm{~g}$ of dry weight per day. ${ }^{1}$ This mixture was found by trial and error to be palatable. Although the animals were left slightly hungry at the end of the feeding and consequently ate the entire portion with food scatter estimated at less than $5 \%$, each animal gained a small amount of weight (averaging 2.1 $\mathrm{kg}$ ) over the 120 day study (Table I). Blood was drawn from the antecubital vein with the aid of Sernylan anesthesia $(11)^{2}$ before the beginning of the high cholesterol intake and at intervals thereafter; the serum was separated and frozen for subsequent analysis in batches.

4-7 wk after beginning the diets each animal was injected intravenously with cholesterol-4- ${ }^{14} \mathrm{C}\left(4.4\right.$ to $\left.5.6 \times 10^{7} \mathrm{cpm}\right)$. The cholesterol-4- ${ }^{14} \mathrm{C}$ was prepared in one of two ways; in two experiments the cholesterol was dissolved in normal saline with the aid of Tween $20(12),{ }^{3}$ and in three instances it was dissolved in acetone and equilibrated in plasma as described by Goodman and Noble (2) before administration. Since the results obtained following these two studies were similar, the data have been treated together. After the cholesterol- $4-{ }^{14} \mathrm{C}$ administration, blood was drawn at 1 , $2,4,7,11$, and 14 days and weekly thereafter for the duration of the study. At the beginning and end of each study

\footnotetext{
${ }^{1}$ The diet was prepared each day as follows: $3 \mathrm{~g}$ of cholesterol- ${ }^{3} \mathrm{H}$ was dissolved in $22 \mathrm{~g}$ of triolein (Nutritional Biochemicals Corp., Cleveland, Ohio.). This mixture was then poured into a Waring Blendor in which had been mixed $250 \mathrm{~g}$ of Purina Laboratory Chow (Ralston Purina Co., St. Louis, Mo.) and $400 \mathrm{ml}$ of $\mathrm{H}_{2} \mathrm{O}$. After the mixture had been blended, it was allowed to dry overnight in room air until it had reached a semisolid form in which it was fed to the animals. Each day's diet contained $34 \mathrm{~g}$ of fat and $38 \mathrm{~g}$ of protein.

2 The Sernylan used in these studies was a gift of Parke, Davis and Co., Detroit, Mich. through Dr. A. C. Bratton, Jr. and Dr. Graham Chen.

${ }^{3}$ City Chemical Corp., New York.
} 
Menghini needle biopsies of the liver were obtained under Sernylan anesthesia for the in vitro measurement of hepatic cholesterol synthesis from acetate-2-14 $\mathrm{C}$; these studies will be reported separately.

Carcass, serum, and diet analyses. At the end of the 120 day experimental period each animal was anesthetized with the aid of Sernylan and Nembutal (Abbott Laboratories, North Chicago, Ill.) and then bled to death. The gastroin- testinal tract was removed, opened, and washed free of feces and unabsorbed food. The entire carcass including the central nervous system, washed gastrointestinal tract, and shed blood were combined together in large glass containers and covered with approximately 25 liters of ethanol. Potassium hydroxide was added to the container (an average of $7.5 \mathrm{~kg}$ of $\mathrm{KOH}$ was required for each carcass), and the mixture was allowed to dissolve at room

TABLE I

Comparison of Two Methods for Assessment of the Size of the Cholesterol Pools in the Baboon

\begin{tabular}{|c|c|c|c|c|c|c|c|}
\hline & \multicolumn{5}{|c|}{ Animal } & \multirow{2}{*}{\multicolumn{2}{|c|}{ Mean \pm SEM }} \\
\hline & 1 & 2 & 3 & 4 & 5 & & \\
\hline \multicolumn{8}{|l|}{ Carcass analysis following cholesterol-H feeding } \\
\hline a. Duration of feeding, days & 120 & 120 & 120 & 120 & 120 & & \\
\hline b. Food intake, $g / d a y$ & 275 & 275 & 275 & 275 & 275 & & \\
\hline c. Cholesterol intake, $g / d a y$ & 3.0 & 3.0 & 3.0 & 3.0 & 3.0 & & \\
\hline $\begin{array}{l}\text { d. Weight, beginning, } k g \\
\text { end, } k g \\
\text { gain, } k g\end{array}$ & $\begin{array}{r}19.1 \\
20.4 \\
1.3\end{array}$ & $\begin{array}{r}18.2 \\
20.7 \\
2.5\end{array}$ & $\begin{array}{r}24.2 \\
25.5 \\
1.3\end{array}$ & $\begin{array}{r}21.8 \\
24.3 \\
2.5\end{array}$ & $\begin{array}{r}22.3 \\
25.0 \\
2.7\end{array}$ & $\begin{array}{r}21.1 \\
23.2 \\
2.1\end{array}$ & $\begin{array}{l} \pm 1.0 \\
\pm 1.1 \\
\pm 0.3\end{array}$ \\
\hline $\begin{array}{l}\text { e. Serum cholesterol concentration } \\
\text { beginning, } m g / 100 \mathrm{ml} \\
\text { end, } m \mathrm{~g} / 100 \mathrm{ml}\end{array}$ & $\begin{array}{l}79 \\
91\end{array}$ & $\begin{array}{r}65 \\
107\end{array}$ & $\begin{array}{l}146 \\
142\end{array}$ & $\begin{array}{l}133 \\
118\end{array}$ & $\begin{array}{l}108 \\
140\end{array}$ & $\begin{array}{l}106 \\
120\end{array}$ & $\begin{array}{l} \pm 15 \\
\pm 10\end{array}$ \\
\hline $\begin{array}{l}\text { f. Dietary cholesterol-^H specific activity, } \\
c p m / m g\end{array}$ & 3169 & 3239 & 5603 & 5634 & 5147 & & \\
\hline $\begin{array}{l}\text { g. Serum cholesterol-3H specific activity at } \\
\text { time of death, } \mathrm{cpm} / \mathrm{mg}\end{array}$ & 2472 & 2527 & 2970 & 3355 & 3340 & & \\
\hline $\begin{array}{l}\text { h. Total carcass cholesterol }[\mathrm{A}+\mathrm{B}+\mathrm{C}] \text {. } \\
\quad \mathrm{g} \\
\mathrm{mg} / \mathrm{kg} \text { body } w t\end{array}$ & $\begin{array}{l}30.8 \\
1509\end{array}$ & $\begin{array}{c}33.4 \\
1614\end{array}$ & $\begin{array}{c}31.2 \\
1223\end{array}$ & $\begin{array}{l}28.4 \\
1169\end{array}$ & $\begin{array}{l}29.5 \\
1180\end{array}$ & $\begin{array}{l}30.7 \\
1339\end{array}$ & $\begin{array}{l} \pm 0.8 \\
\pm 93\end{array}$ \\
\hline i. Total carcass cholesterol-8 $\mathrm{H}, c p m \times 10^{-7}$ & 4.22 & 4.80 & 5.98 & 6.19 & 6.77 & & \\
\hline $\begin{array}{l}\text { j. Carcass cholesterol- }{ }^{-3} \mathrm{H} \text { specific activity, } \\
c p m / m \xi\end{array}$ & 1436 & 1372 & 1912 & 2180 & 2194 & & \\
\hline $\begin{array}{l}\text { k. Total exchangeable cholesterol pools } \\
\qquad\left[\mathrm{A}+\mathrm{B}=\frac{\text { line } i}{\text { line } g \times 1000}\right], \mathrm{g} \\
\mathrm{mg} / \mathrm{kg} \text { bod } \mathrm{w} t\end{array}$ & $\begin{array}{l}17.1 \\
838\end{array}$ & $\begin{array}{l}19.0 \\
918\end{array}$ & $\begin{array}{ll}20.1 \\
788\end{array}$ & $\begin{array}{l}18.4 \\
757\end{array}$ & $\begin{array}{l}18.8 \\
752\end{array}$ & $\begin{array}{l}18.7 \\
811\end{array}$ & $\begin{array}{l} \pm 0.5 \\
\pm 31\end{array}$ \\
\hline $\begin{array}{l}\text { i. Total nonexchangeable cholesterol pool } \\
{[\mathrm{C}=\text { line } h-\text { line } k], \mathrm{g}} \\
\mathrm{g} / \mathrm{kg} \text { body wt }\end{array}$ & $\begin{array}{l}13.6 \\
667\end{array}$ & $\begin{array}{l}14.4 \\
696\end{array}$ & $\begin{array}{l}11.1 \\
435\end{array}$ & $\begin{array}{l}10.0 \\
412\end{array}$ & $\begin{array}{l}10.7 \\
428\end{array}$ & $\begin{array}{l}12.0 \\
528\end{array}$ & $\begin{array}{l} \pm 0.9 \\
\pm 63\end{array}$ \\
\hline \multicolumn{8}{|l|}{ Analysis of cholesterol-14 C die-away curve } \\
\hline m. Duration of study following injection, days & 70 & 70 & 85 & 85 & 85 & & \\
\hline n. Injection medium, & Tween 20 & Tween 20 & Lipoprotein & Lipoprotein & Lipoprotein & & \\
\hline o. $\mathbf{R}_{\mathbf{A}}$ (amount injected), $c p m \times 10^{-7}$ & 5.6 & 5.5 & 4.8 & 4.4 & 4.5 & & \\
\hline p. $\mathrm{C}_{\mathrm{A}}$ (No. 1, Appendix), $c p m / m g$ & 7400 & 5100 & 6750 & 5800 & 6500 & & \\
\hline q. Св (No. 1, Appendix), cpm/mg & 1575 & 1400 & 900 & 1250 & 620 & & \\
\hline r. $T_{\frac{1}{3}}$ of first exponential, days & 3.0 & 3.5 & 3.0 & 2.8 & 3.4 & & \\
\hline s. $T_{1}$ of second exponential, days & .23 & 30 & 35 & 37 & 34 & & \\
\hline $\begin{array}{l}\text { t. Size of pool A (No. 2, Appendix), } \\
\quad \begin{array}{l}g \\
m g / k g \text { body } w t\end{array}\end{array}$ & $\begin{array}{l}6.2 \\
304\end{array}$ & $\begin{aligned} 8.5 \\
411\end{aligned}$ & $\begin{array}{l}6.3 \\
247\end{array}$ & $\begin{array}{l}6.2 \\
255\end{array}$ & $\begin{aligned} 6.3 \\
252\end{aligned}$ & $\begin{aligned} 6.7 & \\
294 & -1\end{aligned}$ & $\begin{array}{l} \pm 0.4 \\
\pm 31\end{array}$ \\
\hline $\begin{array}{l}\text { u. Production rate (No. 5, Appendix), } \\
m g / \text { day } \\
m g / k g \text { body w! per day }\end{array}$ & $\begin{array}{r}662 \\
32\end{array}$ & $\begin{array}{r}635 \\
31\end{array}$ & $\begin{array}{r}642 \\
25\end{array}$ & $\begin{array}{r}487 \\
20\end{array}$ & $\begin{array}{r}721 \\
29\end{array}$ & $\begin{array}{r}629 \\
27\end{array}$ & $\begin{array}{l} \pm 39 \\
\pm 2\end{array}$ \\
\hline v. $k_{\mathrm{AA}}$ (No. 3, Appendix), & -0.195 & -0.160 & -0.206 & -0.207 & -0.188 & -0.191 & \pm 0.008 \\
\hline w. $k$ BB (No. 4, Appendix), & -0.066 & -0.061 & -0.045 & -0.059 & -0.036 & -0.053 & \pm 0.007 \\
\hline x. $k_{\mathrm{BA}}$ (No. 6, Appendix), & 0.066 & 0.061 & 0.045 & 0.059 & 0.036 & 0.053 & \pm 0.007 \\
\hline y. $k_{\mathrm{A}}$ (No. 7. Appendix), & 0.090 & 0.065 & 0.101 & 0.078 & 0.113 & 0.091 & \pm 0.009 \\
\hline z. $k_{\mathrm{AB}}$ (No. 8, Appendix), & 0.105 & 0.095 & 0.106 & 0.129 & 0.075 & 0.102 & \pm 0.009 \\
\hline $\begin{array}{l}\text { aa. Size of pool B (No. 9, Appendix), } \mathrm{g} \\
\mathrm{mg} / \mathrm{kg} \text { body } w t\end{array}$ & $\begin{aligned} 9.9 \\
485\end{aligned}$ & $\begin{array}{l}13.2 \\
638\end{array}$ & $\begin{array}{l}14.8 \\
580\end{array}$ & $\begin{array}{l}13.6 \\
560\end{array}$ & $\begin{array}{l}13.0 \\
520\end{array}$ & 557 & $\begin{array}{l} \pm 0.8 \\
\pm 26\end{array}$ \\
\hline$b b$. Size of pools $\mathrm{A}+\mathrm{B}[t+a a],{ }_{m g / k g}$ body wt & $\begin{array}{l}16.1 \\
789\end{array}$ & $\begin{array}{ll}21.7 \\
1048\end{array}$ & $\begin{array}{ll}21.1 \\
827\end{array}$ & $\begin{array}{l}19.8 \\
815\end{array}$ & $\begin{array}{l}19.3 \\
772\end{array}$ & $\begin{array}{l}19.6 \\
850\end{array}$ & $\begin{array}{l} \pm 1.0 \\
\pm 50\end{array}$ \\
\hline
\end{tabular}


temperature for 7-10 days with the aid of a mechanical stirrer. In two instances the process was speeded by placing the containers on a steam bath for 2 days. At the end of this period the mixture consisted of a translucent brown fluid with a sediment of salts. The volume was then made up to 44 liters with ethanol and stirred for several hours. Aliquots (2-ml) were then removed in quadruplicate for analysis of cholesterol content and of cholesterol $-{ }^{3} \mathrm{H}$ and cholesterol $-{ }^{14} \mathrm{C}$. In three experiments $1 \mathrm{~g}$ portions of 21 different tissues were dissected and removed before the processing of the carcass. These samples were mixed with $0.5 \mathrm{ml} 10 \mathrm{~N}$ $\mathrm{KOH}$ and $2 \mathrm{ml}$ of water and saponified in an autoclave at $15 \mathrm{lb}$. pressure for $30 \mathrm{~min}$. Finally, a sixth baboon not included in the feeding study was subjected to total body dissection for the purpose of assessing the tissue weights per kilogram of body weight in this species.

A $20 \mathrm{~g}$ portion of each diet was extracted in boiling chloroform-methanol. The mixture was filtered, and the filtrate was diluted to $100 \mathrm{ml}$ with methanol. $10-\mathrm{ml}$ aliquots were taken to dryness, and the residue was refluxed on a steam bath in ethanolic $\mathrm{KOH}$ until all oil droplets had disappeared; these samples were processed along with the carcass and serum. 2-ml aliquots of the serum were mixed with $0.5 \mathrm{ml} 10 \mathrm{~N} \mathrm{KOH}$ and saponified in an autoclave at $15 \mathrm{lb}$. pressure for $30 \mathrm{~min}$.

Cholesterol analyses. After saponification each biological sample was made up to contain $10 \mathrm{ml}$ of water:ethanol $(1: 1)$. The samples were extracted two times with 100 $\mathrm{ml}$ of petroleum ether on a shaking machine. The petroleum ether extracts were combined and taken to dryness by boiling on a steam bath. The residue was dissolved in ethanol: acetone $(1: 1)$, and steroid digitonides were precipitated and washed by the Sperry-Webb technique (13). The dried digitonides were dissolved in $4.5 \mathrm{ml}$ of methanol; two $1-\mathrm{ml}$ aliquots were removed for measurements of cholesterol content (13), and two aliquots were added to a solution of $0.5 \%$ diphenyloxazole in toluene for assay of radioactivity. The radioactivity measurements were performed in a Beckman * dual channel spectrometer programmed in such a manner that no tritium counts were observed in the ${ }^{14} \mathrm{C}$ channel, while $32 \%$ of the ${ }^{14} \mathrm{C}$ counts were recovered in the ${ }^{3} \mathrm{H}$ channel.

In order to determine whether the steroid digitonides contained principally cholesterol, sterols were regenerated from serum, diet, and carcass digitonides in two experiments as described by Sperry (14). When aliquots of these samples were chromatographed by gas-liquid chromatography $(3 \%$ $\mathrm{Qf}_{1}$ on Gas Chrom Q), no peaks other than cholesterol were observed, and an average of $98 \%$ of the radioactivity was recovered in the cholesterol area. Similar aliquots were also analyzed by thin-layer chromatography (benzene: ethyl acetate, $3: 1)$; again no other steroid areas were demonstrated when the plate was developed in anisaldehyde, and an average of $91 \%$ of the radioactivity was present in the cholesterol area, the remainder being spread diffusely across the plates. Finally, an aliquot of the dietary cholesterol- ${ }^{8} \mathrm{H}$ together with carrier cholesterol was subjected to dibromination by the method of Fieser (15); the specific activity of this cholesterol was $2125 \mathrm{cpm} / \mathrm{mg}$ before dibromination and $2138 \mathrm{cpm} / \mathrm{mg}$ after dibromination. From these studies it was concluded that cholesterol is the major steroid measured under the conditions of this study, and that the cholesterol specific activities are reliable.

Preparation of radioactive cholesterol. The dietary cholesterol was prepared by adding cholesterol-1 $\alpha-{ }^{8} \mathrm{H}$ (Nuclear-

‘ Beckman Instruments, Palo Alto, Calif.
Chicago Corporation, ${ }^{5} 390 \mathrm{mCi} / \mathrm{mmole}$ ) to cholesterol ( $\mathrm{Nu}$ tritional Biochemicals) which had been recrystallized five times from ethanol; the mixture was dissolved in boiling ethanol, recrystallized, and dried. Each animal was fed cholesterol from a single batch for the duration of the study. The cholesterol-4- ${ }^{14} \mathrm{C}$ was obtained from New England Nuclear Corp. ${ }^{6}(10.25 \mathrm{mCi} / 1.67 \mathrm{mg})$.

\section{RESULTS}

The baboons in this study were maintained on a constant intake of a diet high in cholesterol ${ }^{8} \mathrm{H}$ for 120 days. 4-7 wk after beginning of the feeding, each animal was injected intravenously with a single dose of cholesterol${ }^{14} \mathrm{C}$. A representative experiment in which the change in serum cholesterol specific activity for the two isotopes has been plotted with time is illustrated in Fig. 2. Within 30-50 days after beginning of the cholesterol feeding an isotopic steady state was approximated in each of the five animals and changed little thereafter: the specific activity of serum in these animals averaged $78,78,53,59$, and $65 \%$ of the dietary cholesterol specific activity. The semilogarithmic plot of specific radioactivity for ${ }^{14} \mathrm{C}$ described a curve for the first 3 wk and thereafter following a straight line in all of the animals studied. As is true in man $(2,5,6)$ when the terminal linear portion of the curve is extrapolated back to the injection time and subtracted from the experimental curve, the difference values followed a straight line, thus conforming to a two pool model $(3,4)$.

The results of both the carcass analyses of these animals and the parameters calculated from the dieaway curves are described in Table I. The feeding of $3 \mathrm{~g}$ of dietary cholesterol dissolved in triolein to these animals for 4 months had only a slight effect on the average serum cholesterol value; the mean increase of $14 \mathrm{mg} / 100 \mathrm{ml}$, while not statistically significant, is similar to the results observed by Strong, Rosal, Deupree, and McGill in baboons given a high cholesterol intake for a year (16) and indicates that the serum cholesterol of this species like that of man $(17,18)$ is relatively stable when large amounts of cholesterol are fed. The total carcass cholesterol in these animals varied from 28.4 to $33.4 \mathrm{~g}$, corresponding to a value of $1.3 \pm 0.1 \mathrm{~g} / \mathrm{kg}$ body weight. Since an isotopic steady state for the fed cholesterol- ${ }^{3} \mathrm{H}$ was approximated in each animal, it was possible to measure the total exchangeable pool in this study by the following formulation (Table I, line $k$ ) :

Total' exchangeable carcass cholesterol (g)

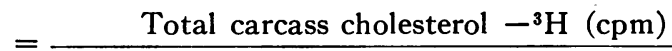

$$
\begin{aligned}
& \text { Serum cholesterol }-{ }^{3} \mathrm{H} \text { specific activity } \\
& \text { at the time of death }(\mathrm{cpm} / \mathrm{g})
\end{aligned}
$$

\footnotetext{
${ }^{5}$ Des Plaines, Ill.

Boston, Mass.
} 


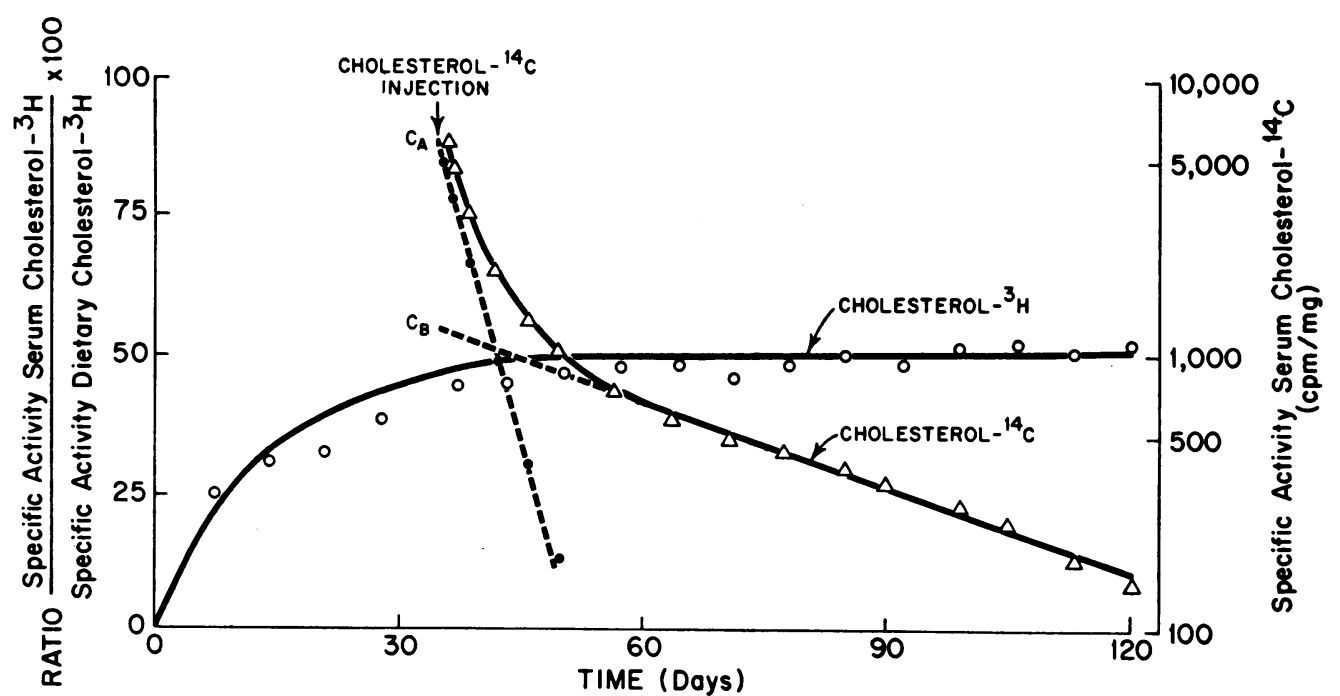

FIgURE 2 Change in serum cholesterol- ${ }^{3} \mathrm{H}$ and $-^{14} \mathrm{C}$ specific activity with time in a baboon fed cholesterol $-{ }^{3} \mathrm{H}$ and injected with cholesterol $-{ }^{14} \mathrm{C}$. The ratio of the serum cholesterol- ${ }^{8} \mathrm{H}$ specific activity to that of the dietary cholesterol $-{ }^{8} \mathrm{H}$ specific activity is shown by the open circles. The experimental values observed for the serum cholesterol $-{ }^{14} \mathrm{C}$ specific activity are represented by triangles. Extrapolation of the terminal linear portion of the ${ }^{14} \mathrm{C}$ line back to the time of injection provides the intercept $C_{B}$ (dashed line). Subtraction of this extrapolated line from the experimental ${ }^{14} \mathrm{C}$ specific activity values provides the difference values shown as solid circles; the projection of the line drawn from these circles back to the time of injection provides the intercept $\mathrm{C}_{\mathbf{A}}$.

This estimation is possible since in the isotopic steady state approached during the last 90 days of the experiments the serum cholesterol specific activity approximates the specific activity for all exchangeable pools. The values obtained in this calculation should equal the size of pools A plus B if the two pool model provides a valid working description of cholesterol metabolism in this animal. This exchangeable pool varied from 17.1 to $20.1 \mathrm{~g}$, corresponding to $0.8 \pm 0.03 \mathrm{~g} / \mathrm{kg}$ of weight.

The nonexchangeable cholesterol pool (C) can likewise be estimated by subtracting the size of the total exchangeable pool in each instance from the total carcass cholesterol. It should be recognized that this moiety may include many pools which exchange more slowly than would be detected in a 4 month feeding study, as well as truly nonexchanging pools. The estimated values for pool $\mathrm{C}$ are given in line $l$ of Table I and ranged from 10.0 to $14.4 \mathrm{~g}$ or $0.5 \pm 0.06 \mathrm{~g} / \mathrm{kg}$ of body weight. This equals nearly $40 \%$ of the total carcass cholesterol. It is of interest in this regard that the brain and spinal cord in this study accounted on an average for only $584 \mathrm{mg}$ of pool $\mathrm{C}$ per animal, and consequently it can be concluded that such a pool or pools must be more ubiquitous than has previously been recognized.

The cholesterol ${ }^{14} \mathrm{C}$ die-away curves for these animals were remarkably consistent. This $t_{t}$ of the first exponential varied from 2.8 to 3.5 days, and that of the second exponential from 23 to 37 days. The size of pool $A$ has been estimated by the formulation $R_{\mathbf{A}} /\left(\mathrm{C}_{\mathbf{A}}+\mathrm{C}_{\mathbf{B}}\right)$ and varied from 6.2 to $8.5 \mathrm{~g}$ (line $t$, Table I) or $0.3 \pm 0.03$ $\mathrm{g} / \mathrm{kg}$ of weight. The size of pool $\mathrm{B}$ has been determined, assuming no independent entry or exit from the pool, as described by Gurpide et al. (3) :

$$
\mathrm{M}_{\mathrm{B}}=\mathrm{M}_{\mathrm{A}}\left(\frac{k_{\mathrm{AB}}}{k_{\mathrm{BA}}}\right)
$$

In this study pool B varied from 9.9 to $14.8 \mathrm{~g}$ corresponding to $0.6 \pm 0.03 \mathrm{~g} / \mathrm{kg}$ of weight (line $a a$, Table I). If the assumption that entry and exit from pool B takes place almost exclusively through pool $\mathrm{A}$ is a valid one, then the sum of pools $\mathrm{A}$ and $\mathrm{B}$ should equal the size of the total exchangeable pool measured directly. This value is given in line $b b$ of Table I; not only does the mean value for the two pools $A+B$ resemble closely that of the total exchangeable pools (line $k$ ), $19.6 \pm 1.0$ and $18.7 \pm 0.5 \mathrm{~g}$ or $0.8 \mathrm{~g} / \mathrm{kg}$ in each instance, but in no individual case do the estimates vary more than $12 \%$. In view of the fact that both the isotopic steady state and the kinetic analyses are subject to a variety of methodological limitations, the striking agreement of the two types of estimation has been interpreted as substantive support for the concept that the cholesterol in pool B is predominantly derived from and disposed of through pool A. 
It should be emphasized again, however, that these results do not prove that $s_{B}$ is zero; this can be easily demonstrated by estimating the size of pool B if $s_{B}$ were 10 or $20 \%$ of the total metabolic production rate; in this instance net flux from $B$ to $A$ has to exceed the net flux in the other direction by an amount equal to the absolute quantity entering pool B directly, and it is possible to solve for the size of pool B which equals the absolute amount exchanging divided by the rate constant $k_{\mathbf{B} \mathbf{A}}$. If $s_{\mathbf{B}}$ equaled $20 \%$ of the metabolic production rate, then pool $B$ would on an average equal $17.2 \mathrm{~g}$, and pool A + B thus would total $23.9 \mathrm{~g}$, a value nearly $25 \%$ higher than measured here.

However, if $s_{\mathrm{B}}$ equaled $10 \%$ of the metabolic production rates, then pool $\mathrm{B}$ would average $14.0 \mathrm{~g}$, and pool $A+B$ would average $20.7 \mathrm{~g}$, a value $10 \%$ higher than the directly measured $18.7 \mathrm{~g}$ and $5 \%$ higher than the $19.6 \mathrm{~g}$ estimated from the die-away curves. Therefore, two general conclusions appear warranted. First, $s_{B}$ probably is so low ( $10 \%$ or less of $s_{\Delta}$ ) that in the assessment of exchangeable pool size in terms of the two pool model by the techniques used here it is safe to assume that it approximates zero. Second, if $s_{B}$ represents $10 \%$ or less of the metabolic turnover rate (i.e. if $s_{\mathrm{B}}$ is of the order of magnitude of $63 \mathrm{mg} / \mathrm{day}$ ), it must also be kept in mind that an equal amount of loss may also occur through $k_{\mathrm{B}}$ by desquamation of hair and skin epithelial cells, nails, sebum, cerumen, etc. Considered together, however, these calculations serve to strengthen the concept of a two pool model in which primary entry and exit into the system occur through the more rapidly exchanging pool as a valid first approximation for cholesterol metabolism in this species.

It is possible furthermore to extend the techniques applied here to individual tissues for a more detailed anatomical dissection of the exchangeable and nonexchangeable cholesterol pools within the body. The rationale for these measurements in tissues from animals in an apparent isotopic steady state for one isotope $\left({ }^{8} \mathrm{H}\right)$ and having received a single injection of a second isotopically labeled cholesterol $\left({ }^{14} \mathrm{C}\right)$ is as follows:

Total tissue cholesterol $=$ Tissue $[\mathrm{A}+\mathrm{B}+\mathrm{C}]$ (mg)

Tissue exchangeable $[\mathrm{A}+\mathrm{B}]$ cholesterol (mg)

$$
=\frac{\text { Tissue cholesterol- }{ }^{3} \mathrm{H}(\mathrm{cpm})}{\begin{array}{c}
\text { Serum cholesterol- }{ }^{3} \mathrm{H} \\
\text { specific activity }(\mathrm{cpm} / \mathrm{mg})
\end{array}}
$$

Tissue nonexchange- $=[\mathrm{A}+\mathrm{B}+\mathrm{C}]-[\mathrm{A}+\mathrm{B}]$ able [C] or very slowly exchangeable cholesterol (mg)

It is not possible at present to assess with certainty the amount of cholesterol in each tissue which is part of pools $\mathrm{A}$ and $\mathrm{B}$, but it is possible to make a minimal estimate of the size of pool $B$ within a given tissue since at the time of death the mean specific activity of ${ }^{14} \mathrm{C}$ cholesterol in pool B should exceed that of the serum (pool A). Such a situation must exist as long as cholesterol unlabeled with ${ }^{14} \mathrm{C}$ enters a rapidly turning over pool such as pool A (from synthesis and absorption) and mixes with that moiety exchanging from the more slowly turning over pool; thus, after the decay slope becomes linear, the average specific activity in pool B must exceed that of pool A, and consequently it is possible to identify those tissues which contain a large component of pool B :

Tissue pool $\mathrm{B}_{\min }$ (per cent of $\mathrm{A}+\mathrm{B}$ )

$$
=\frac{X-Y}{X} \times 100 \text { where: }
$$

$X=$ Cholesterol-14 $\mathrm{C}$ specific activity of tissue pool $[\mathrm{A}+\mathrm{B}], \mathrm{cpm} / \mathrm{mg}$

$Y=$ Serum cholesterol ${ }^{14} \mathrm{C}$ specific activity at time of death, $\mathrm{cpm} / \mathrm{mg}$

This method, while clearly identifying those tissues which do contain a significant pool of $\mathrm{B}$, provides only a minimal estimate of its size since the correction for pool A may be too large in a given tissue due to the fact that the specific activity of pool A represents a net value of a large number of pools with a rapid turnover, and consequently the correction factor used for all tissues for contamination with pool A may be in error in the case of individual tissues. Furthermore, this technique does not allow the differentiation of a true intracellular pool A from contamination with blood. With these limitations in mind, however, the data obtained in this manner are very interesting. The specific activities of serum, tissue, and total carcass cholesterol in baboons 3,4 , and 5 at the time of death are listed in Table II, and the mean estimates of the tissue pools derived from these specific activities are summarized in Fig. 3 in which the tissue compartmental analyses have been expressed in the following three ways: as the percentage breakdown of each compartment as the per cent of the total cholesterol in each tissue (panel A); as the actual amount of each compartment per gram of tissue weight (panel B) ; and as the total amount of each compartment in each tissue projected to the unit weight of the animal (panel C). Several features of this study deserve comment. First of all, the nonexchangeable or very slowly exchangeable tissue pool $\mathrm{C}$ is not limited to the central nervous system but is found in varying degree in several body compartments including bone, skin, and muscle where it might have been predicted, as well as in several tissues (adrenal, testis, and colon) in which cholesterol synthesis is appreciable. Pool A accounts 
TABLE II

The Specific Activities of Serum, Tissue, and Total Carcass Cholesterol at the Time of Death

\begin{tabular}{|c|c|c|c|c|c|c|}
\hline & \multicolumn{2}{|c|}{ Baboon 3} & \multicolumn{2}{|c|}{ Baboon 4} & \multicolumn{2}{|c|}{ Baboon 5} \\
\hline & ${ }^{14} \mathrm{C}$ & ${ }^{2} \mathrm{H}$ & ${ }^{14} \mathrm{C}$ & ${ }^{3} \mathrm{H}$ & ${ }^{14} \mathrm{C}$ & ${ }^{3} \mathrm{H}$ \\
\hline & \multicolumn{2}{|c|}{$c p m / m g$} & \multicolumn{2}{|c|}{$c p m / m g$} & \multicolumn{2}{|c|}{$c p m / m s$} \\
\hline Terminal serum & 165 & 2970 & 120 & 3355 & 196 & 3340 \\
\hline Skin & 181 & 1822 & 110 & 1805 & 164 & 1578 \\
\hline Muscle & 329 & 2433 & 188 & 1552 & 405 & 2286 \\
\hline Liver & 178 & 2925 & 146 & 3411 & 218 & 3205 \\
\hline Bile & 157 & 2850 & 119 & 3465 & 194 & 3122 \\
\hline Spleen & 163 & 2858 & - & 3364 & 192 & 3254 \\
\hline Lung & 174 & 3024 & 124 & 3531 & 210 & 3173 \\
\hline Heart & 118 & 2611 & 113 & 2920 & 236 & 3301 \\
\hline Kidney & 260 & 3070 & 181 & 3340 & 293 & 2866 \\
\hline Adipose tissue & 326 & 2578 & 253 & 3002 & 328 & 2890 \\
\hline Testis & 166 & 2012 & 113 & 1887 & 184 & 2120 \\
\hline Adrenal & 196 & 2482 & 128 & 3302 & 201 & 2982 \\
\hline Diaphragm & 118 & 2611 & 110 & 2169 & 258 & 3208 \\
\hline Lymph nodes & 190 & 2902 & 81 & 3226 & 231 & 3187 \\
\hline Brain & 14 & 60 & 10 & 115 & 25 & 98 \\
\hline Aorta & 220 & 2892 & 254 & 2193 & 387 & 2088 \\
\hline Esophagus & 233 & 2567 & 120 & 1998 & 242 & 2568 \\
\hline Stomach & 130 & 1800 & 126 & 1518 & 297 & 2400 \\
\hline Small intestine & 101 & 3051 & 52 & 3134 & 125 & 3082 \\
\hline Colon & 142 & 1511 & 93 & 1351 & 217 & 1766 \\
\hline Pancreas & 232 & 2762 & 167 & 3254 & 258 & 3137 \\
\hline Bone & 29 & 1009 & 34 & 2132 & 108 & 1251 \\
\hline Total carcass & 172 & 1912 & 120 & 2180 & 193 & 2194 \\
\hline
\end{tabular}

for all or virtually all of the cholesterol within the blood stream, small intestine, lung, liver, spleen, kidney, and pancreas. A major element of pool $\mathrm{A}$ is also probably located in adipose tissue, muscle, and skin. Pool $B$ on the other hand, accounts for a portion of the cholesterol in several tissues: the various muscles, adipose tissue, skin, and several visceral organs. On a per weight basis the largest component is found in muscle, adipose tissue, and skin. The most interesting problem posed by this formation is that some, if not all tissues have elements of all three compartments.

The tissue specific activities obtained in this paper differ from the previous studies of Chobanian and Hollander (19) and of Field, Swell, Schools, and Treadwell (20) in one important respect; namely, that the specific activity of the injected isotope of some tissues exceeds that of blood after the time when the disappearance curve becomes linear. The reason for this discrepancy is not clear at present; it may derive from the fact that most of the subjects in those studies were individuals who were suffering from terminal cancer. The inevitable inanition which accompanies such a condition would diminish the synthesis and absorption of unlabeled cholesterol and consequently would cause discrepancies between blood and tissues in pool B to diminish. In addition, in neither study was bone or adipose tissue analyzed.

It is of interest that the 21 tissues chosen for this analysis contain about $900 \mathrm{mg}$ of the average of 1191 $\mathrm{mg}$ of total carcass cholesterol per $\mathrm{kg}$ of body weight as determined in these three animals $(3,4$, and 5$)$ by direct carcass analysis; the discrepancy can probably be accounted for by the fact that several tissues (tendon, peripheral nerves, fascia, and omentum) were not analyzed separately. In addition, the data are subject to the limitation that $1 \mathrm{~g}$ aliquots of tissues such as muscle may not be representative of the total body cholesterol content of these tissues. Even with these limitations, however, it is clear that the size of a relatively few pools is massive in comparison with the majority of the body compartments. It is very likely that this feature of cholesterol metabolism explains why the over-all body turnover can be described as consisting of two exchangeable pools rather than the multitudinous pools which must in fact interchange in the intact animal. 


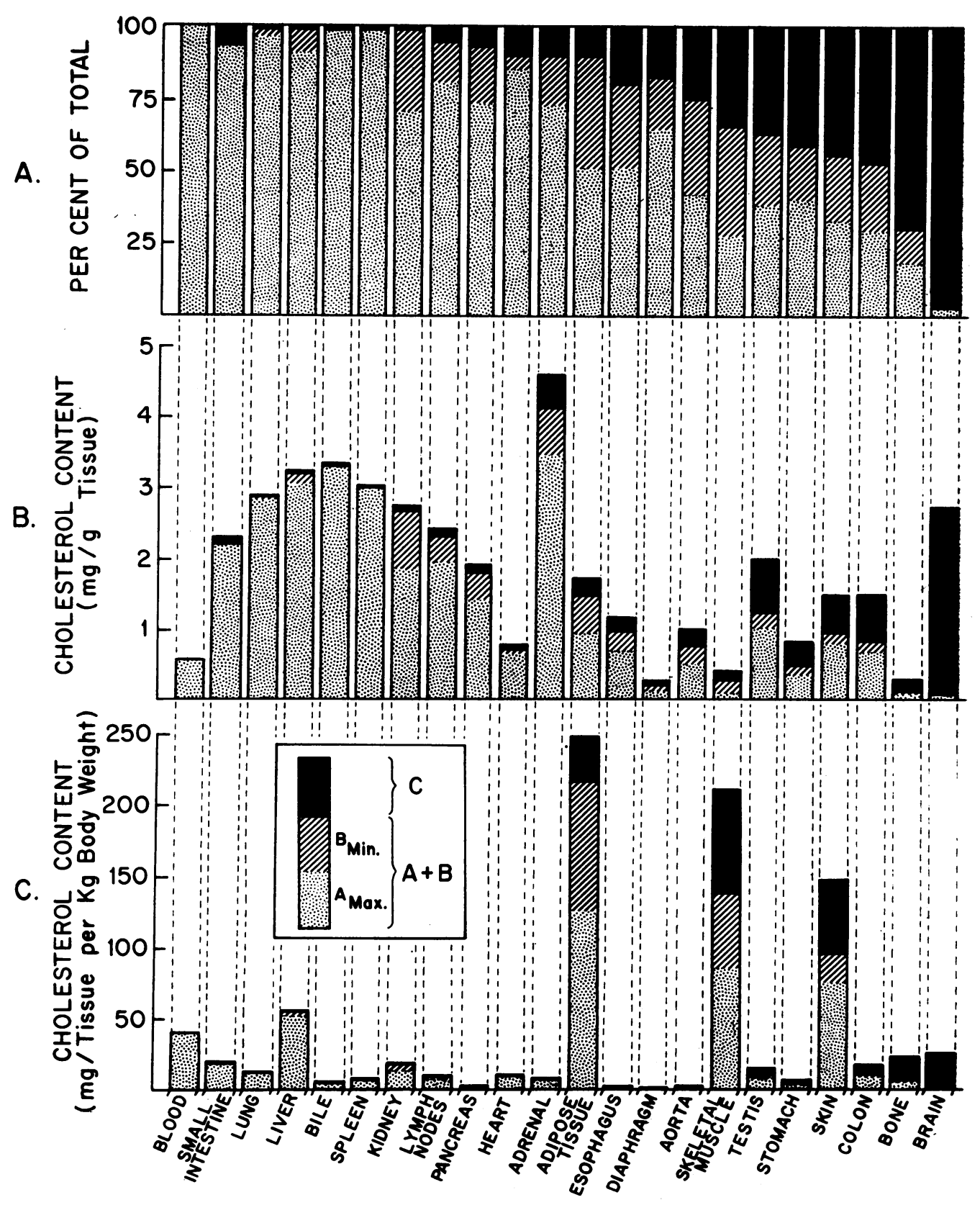

FIGURE 3 The analysis of the cholesterol compartments in 21 tissues of the baboon. The data in Table II have been utilized as described in the text for the approximation of the compartmentalization of cholesterol into the various pools in individual tissues. The mean data for three animals have been expressed in three ways. In panel $A$ the compartments are expressed as percentage values for the individual tissues. In panel $B$ the percentage breakdown has been projected to the cholesterol contents of the various tissues on the basis of milligrams per gram of wet weight. In panel $C$ these projections have been extended to the weight of the entire tissue per kilogram of body weight. Each analysis represents the mean value for three analyses. 


\section{DISCUSSION}

The over-all model for cholesterol metabolism in the baboon which has been deduced in this study is summarized in Fig. 4. Cholesterol in the body is viewed as comprising three general compartments, two exchangeable pools (A and B) and one pool (C) that may include a very slowing turning over as well as totally nonexchangeable cholesterol compartments. Pool $\mathrm{C}$ contains $0.5 \mathrm{~g}$ of cholesterol per $\mathrm{kg}$ of body weight, and pools $\mathrm{A}$ and $\mathrm{B}$ contain $0.3 \mathrm{~g}$ and $0.6 \mathrm{~g}$ per $\mathrm{kg}$ of weight respectively. Entry into the system ( $\left.P R_{\Delta}\right)$ occurs predominantly through pool $\mathrm{A}$ and represents $27 \mathrm{mg} / \mathrm{kg}$ of body weight per day. It has been possible to demonstrate by direct carcass analysis of animals in an isotopic steady state that the measurement of the exchangeable pools A and B by analysis of the cholesterol die-away curve does provide a valid estimate of these pools if one assumes that entry into the system occurs predominantly ( $90 \%$ or greater) through pool $\mathrm{A}$. These results confirm and extend the validity of a two pool model of exchangeable cholesterol within the body $(2,5,6)$. The results are in close agreement, furthermore, with previous estimates from this laboratory that circulating cholesterol is derived almost exclusively from three sources-diet and endogenous synthesis in liver and intestinal tract $(8,9,21)$.

Provided that results obtained in the baboon apply to other species, the implications of these findings are noteworthy. It should be possible to assess the effects of pharmacological, physiological, and dietary manipulation not only on cholesterol balance, the serum concentration, and the size of the rapidly exchangeable pool but on the size of the slowly equilibrating pool as well. Thus, the means are now available for the description of cholesterol metabolism in normal and pathological states with greater precision than heretofore. Indeed, Nestel, Whyte, and Goodman have already explored the relation between body fat and both the production rate and the size of the exchangeable pools of cholesterol and

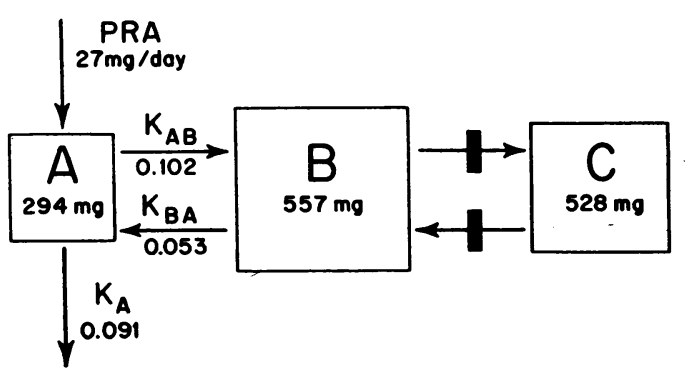

FIGURE 4 The over-all model for cholesterol metabolism in the baboon. The findings in this study have been schematically represented in a figure in which the mean size of pools $A, B$, and $C$ reflect the measured size. All values have been expressed per kilogram of body weight, or as rate constants. have shown that the production rate and the size of pool B (but not of A) are related to excess body weight (6). These results suggest that $s_{B}$ may not approximate zero in all circumstances.

However valid the two pool model may be as an overall approximation of the complex and dynamic state in the living animal, the results of the individual tissue analyses serve to emphasize that the body is actually comprised of a large number of individual compartments, each with its own turnover and exchange rates and sources of cholesterol. The over-all model has meaning only because the major components of pools $\mathrm{A}, \mathrm{B}$, and $C$ constitute such a large fraction of the over-all tissue cholesterol. Consequently, the reservation must be kept in mind that events in individual tissues may not necessarily be reflected in gross shifts in the size of the exchangeable pools just as alterations in serum concentration are not necessarily reflected in changes in over-all cholesterol balance.

Indeed, the implications of the analyses of the various tissue compartments are of considerable interest, even when the limitations of these estimations are kept in mind. Some tissues fall almost exclusively within the category of either the rapidly exchangeable pool or the nonexchangeable pool, whereas the vast majority of the tissue pools contain admixtures of the three compartments in varying degree. Since tissues are composed of different cell lines it is possible of course that this partition represents cholesterol in totally different cell lines and in blood. It is also possible on the other hand that cholesterol turnover and exchange rates in tissues such as muscle might vary within subcellular compartments of a single cell line. The clarification of this issue would require a more detailed breakdown than has been attempted at present. In addition, no attempt has been made in this study to determine the role of cholesteryl esters, either within individual tissues or in the over-all analyses in this compartmentalization.

Furthermore, it is clear that pool $\mathrm{C}$ must be viewed as comprising at least two components when one takes into consideration the over-all size of the organ; the first a vast, truly nonexchangeable pool which is comprised primarily of central nervous tissue, bone, and muscle and in which neither significant cholesterol synthesis nor complete exchange takes place in the adult. The presence of muscle and other tissues rich in fibrous connective tissue in this category raises the possibility that a third exchangeable cholesterol pool, even more slowly turning over, might be delineated within pool $\mathrm{C}$ if the experiment were designed to be conducted for a year or more. It is also true, of course, that additional, very slowly exchanging pools might be delineated by the peel-away technique if the die-away curve for the injected isotope were followed for longer periods of time. 
Therefore, it seems reasonable to conclude that these two methods (kinetic analysis of the die-away curve, and carcass analysis following radioactive cholesterol feeding) have delineated two exchangeable pools which differ considerably from the remainder of the body cholesterol in the ability to exchange with the serum. The second element of pool $\mathrm{C}$, while smaller in relation to the over-all size of the pool would be composed of tissues in which net cholesterol synthesis does take place at an appreciable rate but which probably do not exchange completely with the circulation and which as a consequence make exceedingly low or no net contributions to the circulating level. In this category, testis, colon, adrenal, and skin are striking examples.

One final application of the double isotope technique used in these experiments deserves comment. Since the percentage of circulating cholesterol derived from dietary and from endogenous sources can be estimated in the isotopic steady state, and since the turnover or metabolic production rate can be determined from the die-away curve, it is also possible to determine the amount of dietary cholesterol absorbed each day as well as the amount of daily endogenous cholesterol synthesis. Thus, because of the simplicity of the measurements involved, this means of studying over-all cholesterol metabolism offers several advantages to the more difficult types of estimation utilizing isotopic balance techniques (6).

\section{APPENDIX}

The kinetic analyses have been taken from Gurpide et al. $(3,4)$ and from Goodman and Noble $(2)$.

1. The basic kinetic formula is

$$
a_{t}=C_{A} e^{-\alpha t}+C_{B} e^{-\beta t}
$$

in which $a_{t}$ is specific activity at time $t ; C_{A}$ and $C_{B}$ are the specific activities of exponentials $A$ and $B$ at time zero; $\alpha$ and $\beta$ are 0.69315 per half-life of exponentials $A$ and $B$ respectively; and $\mathrm{e}$ is the natural logarithm.

2. The size of pool $A\left(M_{A}\right)$ is

$$
\mathrm{M}_{\mathrm{A}}=\frac{\mathrm{R}_{\mathrm{A}}}{\mathrm{C}_{\mathrm{A}}+\mathrm{C}_{\mathrm{B}}}
$$

in which $R_{A}$ is the amount of isotope injected (cpm). $\mathrm{A}$ is

3. The rate constant for the total rate of removal from pool

$$
k_{\mathrm{AA}}=\frac{-\alpha \mathrm{M}_{\mathrm{A}} \mathrm{C}_{\mathrm{A}}-\beta \mathrm{M}_{\mathrm{A}} \mathrm{C}_{\mathrm{B}}}{\mathrm{R}_{\mathrm{A}}}
$$

4. The rate constant or the total rate of removal from pool $\mathrm{B}$ is

$$
k_{\mathrm{BB}}=-\left(\alpha+\beta+k_{\mathrm{AA}}\right)
$$

5. The production rate of cholesterol in pool A, assumed to approximate the total turnover rate, is

$$
\mathrm{PR}_{\mathrm{A}}=\frac{\mathrm{R}_{\mathrm{A}} \alpha \beta}{\alpha \mathrm{C}_{\mathrm{B}}+\beta \mathrm{C}_{\mathrm{A}}}
$$

6. The rate constant for the transfer of cholesterol from pool $\mathrm{A}$ to pool $\mathrm{B}$ where the assumption is made that $k_{\mathrm{B}}$ approximates zero is

$$
k_{\mathrm{BA}}=-k_{\mathrm{BB}}
$$

7. The rate constant for the exit of cholesterol from pool A to outside the system is

$$
k_{\mathrm{A}}=\frac{\alpha \beta}{k_{\mathrm{BA}}}
$$

8. The rate constant for the transfer of cholesterol from pool A to pool B is

$$
k_{\mathrm{AB}}=-k_{\mathrm{AA}}-k_{\mathrm{A}}
$$

9. The size of pool $B$ where the basic assumption is made that both $\mathrm{S}_{\mathrm{B}}$ and $k_{\mathrm{B}}$ approximate zero is

$$
\mathrm{M}_{\mathrm{B}}=\mathrm{M}_{\mathrm{A}}\left(\frac{k_{\mathrm{AB}}}{k_{\mathrm{BA}}}\right)
$$

\section{ACKNOWLEDGMENTS}

The able technical assistance of Mary B. Neal, Joanne D. Walker, and George T. Crowley, Jr., in the performance of these studies and of Dr. DeWitt S. Goodman in the organization of the manuscript are gratefully acknowledged.

This work has been supported by grants from the U.S. Public Health Service (AM 8749) and from the American Heart Association.

\section{REFERENCES}

1. Wilson, J. D. 1969. Measurement of the miscible cholesterol pools in the intact animal. J. Clin. Invest. 48: 89a.

2. Goodman, D. S., and R. P. Noble. 1968. Turnover of plasma cholesterol in man. J. Clin. Invest. 47: 231.

3. Gurpide, E., J. Mann, and E. Sandberg. 1964. Determination of kinetic parameters in a two-pool system by administration of one or more tracers. Biochemistry. 3: 1250.

4. Gurpide, E., J. Mann, and S. Lieberman. 1963. Analysis of open systems of multiple pools by administration of tracers at a constant rate or as a single dose as illustrated by problems involving steroid hormones. J. Clin. Endocrinol. Metab. 23: 1155.

5. Samuel, P., C. M. Holtzman, E. Meilman, and W. Perl. 1968. Effect of neomycin on exchangeable pools of cholesterol in the steady state. J. Clin. Invest. 47: 1806.

6. Nestel, P. J., H. M. Whyte, and D. S. Goodman. 1969. Distribution and turnover of cholesterol in humans. J. Clin. Invest. 48 : 982.

7. Grundy, S. M., and E. H. Ahrens, Jr. 1969. Measurements of cholesterol turnover, synthesis, and absorption in man, carried out by isotope kinetic and sterol balance methods. J. Lipid Res. 10: 91.

8. Dietschy, J. M., and J. D. Wilson. 1968. Cholesterol synthesis in the squirrel monkey: relative rates of synthesis in various tissues and mechanisms of control. J. Clin. Invest. $47: 166$.

9. Wilson, J. D. 1968. Biosynthetic origin of serum cholesterol in the squirrel monkey: evidence for a contribution by the intestinal wall. J. Clin. Invest. 47: 175.

10. Hill, W. C. O. 1965. Taxonomy of the baboon. In The Baboon in Medical Research. H. Vagtborg, editor. University of Texas Press, Austin. 2: 3.

11. Vice, T. E., L. D. Claborn, and R. A. Ratner. 1965. Anesthetic technics in the baboon with some observations on other primates. In Experimental Animal Anesthesiology. D. C. Sawyer, Capt. USAF, VC, editor. USAF School of Aerospace Medicine, Brooks AFB, Texas. 301.

12. Meier, J. R., M. D. Siperstein, and I. L. Chaikoff. 1952. $\mathrm{C}^{14}$-cholesterol. IV. Oxidation of carbons 4 and 26 to 
carbon dioxide by surviving tissues. J. Biol. Chem. 198: 105.

13. Sperry, W. M., and M. Webb. 1950. A revision of the Schoenheimer-Sperry method for cholesterol determination. J. Biol. Chem. 187 : 97.

14. Sperry, W. M. 1963. Quantitative isolation of sterols. J. Lipid Res. 4 : 221.

15. Fieser, L. F. 1955. Cholesterol, $\Delta^{5}$-cholesten-3-one, and $\Delta^{4}$-cholesten-3-one. Org. Syn. 35: 43.

16. Strong, J. P., J. Rosal, R. H. Deupree, and H. C. McGill, Jr. 1966. Diet and serum cholesterol levels in baboons. Exp. Mol. Pathol. 5: 82.

17. Connor, W. E., R. E. Hodges, and R. E. Bleiler. 1961. The serum lipids in men receiving high cholesterol and cholesterol-free diets. J. Clin. Invest. 40: 894.
18. Wilson, J. D., and C. A. Lindsey, Jr. 1965. Studies on the influence of dietary cholesterol on cholesterol metabolism in the isotopic steady state in man. J. Clin. Invest. $44: 1805$.

19. Chobanian, A. V., and W. Hollander. 1962. Body cholesterol metabolism in man. I. The equilibration of serum and tissue cholesterol. J. Clin. Invest. 41: 1732.

20. Field, H., Jr., L. Swell, P. E. Schools, Jr., and C. R. Treadwell. 1960. Dynamic aspects of cholesterol metabolism in different areas of the aorta and other tissues in man and their relationship to atherosclerosis. Circulation. 22 : 547.

21. Lindsey, C. A., Jr., and J. D. Wilson. 1965. Evidence for a contribution by the intestinal wall to the serum cholesterol of the rat. J. Lipid Res. 6: 173. 